\title{
Tetramethyl lead absorption: a report of human exposure to a high level of tetramethyl lead
}

\section{J. GETHING}

The Associated Octel Company Limited, Medical Department, Ellesmere Port, Cheshire

\begin{abstract}
Gething, J. (1975). British Journal of Industrial Medicine, 32, 329-333. Tetramethyl lead absorption: a report of human exposure to a high level of tetramethyl lead. Accidental human exposure to a high level of tetramethyl lead is described. Tetramethyl lead is blended with petrol as an antiknock agent, and it has similar physical properties to tetraethyl lead. The patient had high levels of lead in urine, averaging $4.75 \mu \mathrm{mol}(983 \mu \mathrm{g})$ daily for the first four days after exposure and he continued to have raised levels of urinary lead for six months. He had no symptoms or physical signs of lead poisoning and comparisons are made between this case and previously reported cases of poisoning by tetraethyl lead. In the cases of tetraethyl lead poisoning all the patients had symptoms, some severe, yet in no instance did the urinary lead levels approach those described in this patient. The effects of chelation therapy with calcium disodium versenate are discussed and the results are similar to those found in tetraethyl lead poisoning. Blood lead levels of up to $3.91 \mu \mathrm{mol} / 1(81 \mu \mathrm{g} / 100 \mathrm{~g})$ occurred but these levels were not raised commensurate with the urinary lead output. The levels of $\delta$ aminolaevulinic acid (ALA) in the urine were not significantly raised and this report shows that the urinary lead levels give a better guide to the degree of absorption of tetramethyl lead compared with the blood lead or urinary ALA levels. The report illustrates that tetramethyl lead is less toxic to man than tetraethyl lead.
\end{abstract}

The toxic effects of tetraethyl lead in human exposure have been well documented in the past (Boyd, Walker, and Henderson, 1957; Beattie, Moore, and Goldberg, 1972; Cassells and Dodds, 1946; Walker and Boyd, 1952; Barry, 1957) but the effects of excessive exposure to tetramethyl lead have not been reported. Work involving exposure to animals (Cremer, 1959; Springman, Bingham, and Stemmer, 1963; Davis et al., 1963; Cremer and Callaway, 1961) indicated that tetramethyl lead had similar properties to tetraethyl lead but its toxicity on a weight for weight basis was of a lower order. Confirmation of this finding has not previously been made in man.

\section{Case history}

During the evening of 20 January 1972 a 22 -year-old male employee, who had had no previous occupa- tional exposure to lead, was preparing to remove the angle-valve from an autoclave containing tetramethyl lead.

Because of pressure inside the autoclave the valve spindle ejected, knocking him backwards on to the floor. He was unconscious and suffered injuries to the head, face, eyes, chest, and right leg. While lying on the floor his whole body was covered with the contents of the autoclave which flowed through the open valve seat.

The reaction in the autoclave had been completed a considerable time previously and the contents were at room temperature.

The material which covered the patient comprised approximately $30 \%$ tetramethyl lead, the remainder being inorganic lead with small amounts of methyl chloride and toluene.

The patient, still unconscious, was removed from 
the building within five minutes. All his clothing was removed and his skin washed with water before he was taken to the medical centre.

Lead in air levels, taken from a continuous monitoring system give an indication of the extent of contamination in the building:

\section{First floor $\quad 957 \mathrm{mg} / 10 \mathrm{~m}^{3}$ Second floor $3765 \mathrm{mg} / 10 \mathrm{~m}^{3}$}

When seen at the medical centre the patient was unconscious but reacted to moderate stimuli. He was cyanosed with rapid shallow respirations. Autoclave contents covered his hair and eyes and partially blocked his mouth and nose. His airway was cleared and he was given oxygen by face mask.

Examination revealed a $10 \mathrm{~cm}$ laceration of the occipital area of his scalp and numerous abrasions on the face, chest, and arms. There was a large swelling of the lateral aspect of the right leg just below the knee. The pulse rate was $72 /$ minute, of good volume; blood pressure $140 / 90$. Heart sounds were normal and there were crepitations over both lung bases.

He was transferred to hospital where his whole body was washed with soap and water. It was impossible to decontaminate the hair adequately, so his head was shaved. Oxygen therapy was continued and the scalp laceration sutured. The patient regained consciousness 90 minutes after the accident.

Clinical findings in hospital were essentially the same as those found at the medical centre, and in particular there were no abnormal signs in the central nervous system. The following investigations were carried out:

Radiographs of skull, chest, abdomen, pelvis, and both legs: the only positive finding was a comminuted fracture of the right fibula.

$\begin{array}{lr}\text { Haemoglobin } & 11.5 \mathrm{~g} / \mathrm{dl} \mathrm{PCV}: 0.34(34 \%) \\ \text { Plasma sodium } & 113 \mathrm{mmol} / \mathrm{l} \\ \text { Plasma potassium } & 39 \mathrm{mmol} / \mathrm{l} \\ \text { Plasma chloride } & 105 \mathrm{mmol} / \mathrm{l}\end{array}$

His leg was splinted and he was transfused with 2 pints of whole blood.

He remained in hospital for a period of 58 days and recovery from his injuries was complicated by sloughing of the skin over the fracture site, requiring surgical treatment. This delayed his discharge from hospital.

It should be emphasized that at no time did the patient have symptoms which could be related to organic lead poisoning, nor did clinical examination, particularly of the nervous system, reveal any abnormality.

He had no complaints, apart from pain due to his fractured leg, which required pethidine injections for the first three days. He was at all times cheerful, co-operative, and friendly; his appetite remained good and he slept well.
The pulse rate, blood pressure, and temperature are often lowered in cases of tetraethyl lead poisoning, but in this case no change was seen.

During the first week in hospital the pulse rate varied between 80 and 110 per minute, and then settled between 72 and 90 per minute.

When recorded on arrival at hospital the blood pressure level was $150 / 90 \mathrm{~mm} \mathrm{Hg}$. It gradually settled over the next two days to $130 / 80 \mathrm{~mm} \mathrm{Hg}$ where it remained virtually unchanged.

During the first 10 days in hospital the temperature was raised, $90 \%$ of the records being between $36.8^{\circ} \mathrm{C}$ and $37.7^{\circ} \mathrm{C}$. During the remainder of his stay in hospital the temperature was around $36 \cdot 7^{\circ} \mathrm{C}$.

\section{Analytical findings}

The urinary lead was measured by the method of Browett and Moss (1965); the blood lead and faecal lead by the method of Bambach and Burkey (1942); and the urinary ALA by the method of Davis and Andelman (1967).

Table 1 shows the levels of lead in urine from spot samples, blood lead, faecal lead, and urinary $\delta$ aminolaevulinic acid (ALA).

Chelation therapy, which is discussed later, was started on the evening of 25 January and completed on the evening of 27 January.

The urinary lead excretion was considerably raised and increased further by chelation therapy. Blood lead values were also above normal, but did not exceed $3.91 \mu \mathrm{mol} / 1(81 \mu \mathrm{g} / 100 \mathrm{~g})$. The report of Beattie et al. (1972) noted that blood lead values in cases of tetraethyl lead poisoning did not increase to levels commensurate with the marked elevation of the urinary lead.

ALA values in urine did not show evidence of abnormal elevation but an interesting feature of the case was the high faecal lead content noted six days after the accident. He had not had a bowel action up to that time. The $13.3 \mathrm{mg} \mathrm{Pb} / \mathrm{g}$ ash found in the first sample of faeces obtained suggests that the patient must have ingested a large amount of lead at the time of his exposure. Alternatively, as chelation therapy had begun the day before the faeces sample was obtained, it is quite possible that the faecal lead value had been enhanced by chelation. A second faecal sample obtained 12 days later showed a reduction to $0.2 \mathrm{mg} \mathrm{Pb} / \mathrm{g}$ ash, a return to normal values (Kehoe, 1961; Thompson, 1971).

For the first nine days 24-hr samples of urine were collected and the total amount of lead in the samples is shown in the Figure.

The average daily output of lead in the urine before chelation was $4.75 \mu \mathrm{mol}(983 \mu \mathrm{g})$. This does not include the figure for 25 January of $5.89 \mu \mathrm{mol}$ $(1220 \mu \mathrm{g})$, when chelation began at $6.0 \mathrm{pm}$.

The average daily output for the following five days was $19.73 \mu \mathrm{mol}(4085 \mu \mathrm{g})$. This gives a ratio of 
TABLE 1

LEVELS OF LEAD IN URINE

\begin{tabular}{|c|c|c|c|c|c|c|c|}
\hline \multirow{2}{*}{ Date } & \multicolumn{2}{|c|}{ Urinary $P b$} & \multicolumn{2}{|c|}{ Blood Pb } & \multirow{2}{*}{$\begin{array}{c}\text { Faecal Pb } \\
\mu g / g \text { ash }\end{array}$} & \multicolumn{2}{|c|}{$A L A$} \\
\hline & $\mu \mathrm{mol} / \mathrm{l}$ & ( $\mu g /$ litre) & $\mu \mathrm{mol} / \mathrm{l}$ & $(\mu g / 100 g)$ & & $\mu \mathrm{mol} / \mathrm{l}$ & $(m g / l)$ \\
\hline $\begin{array}{r}21.1 .72 \\
22.1 .72 \\
23.1 .72 \\
24.1 .72 \\
25.1 .72 \\
26.1 .72 \\
27.1 .72 \\
28.1 .72 \\
29.1 .72 \\
30.1 .72 \\
31.1 .72 \\
7.2 .72 \\
24.2 .72 \\
22.3 .72 \\
5.4 .72 \\
3.7 .72\end{array}$ & $\begin{array}{r}2.42 \\
2.34 \\
3.36 \\
4.71 \\
3.17 \\
13.91 \\
9.08 \\
5.41 \\
8.74 \\
2.66 \\
2.13 \\
2.56 \\
0.97 \\
1.24 \\
1.06 \\
0.74\end{array}$ & $\begin{array}{r}(500) \\
(484) \\
(696) \\
(976) \\
(656) \\
(2880) \\
(1880) \\
(1120) \\
(1810) \\
(550) \\
(440) \\
(530) \\
(200) \\
(256) \\
(220) \\
(153)\end{array}$ & $\begin{array}{l}1 \cdot 84 \\
2 \cdot 80 \\
3 \cdot 62 \\
2 \cdot 32\end{array}$ & $\begin{array}{l}(37) \\
\\
(52) \\
\\
(38) \\
(58) \\
(75) \\
\\
(48)\end{array}$ & 13300 & $\begin{array}{c}125.90 \\
35.1 \\
28.99 \\
35.1 \\
34.34 \\
76.3 \\
64.86 \\
41.20\end{array}$ & $\begin{array}{r}(16.5) \\
(4 \cdot 6) \\
(3.8) \\
(4 \cdot 6) \\
(4.5) \\
(10.0) \\
(8.5) \\
(5.4)\end{array}$ \\
\hline
\end{tabular}

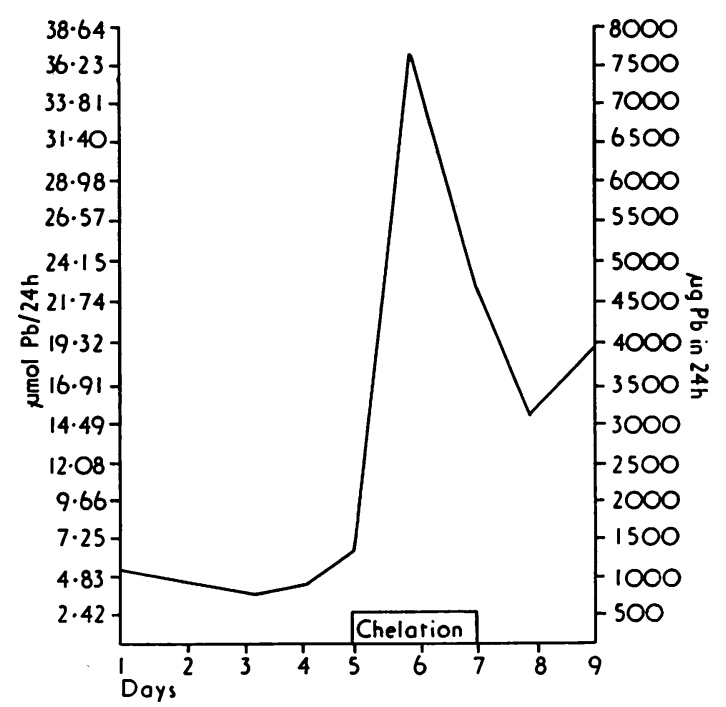

FIGURE 24-hour urine samples.

output after chelation, compared with that before chelation, of over 4 to 1 .

The chelating agent used was calcium disodium versenate, $1.0 \mathrm{~g}$ in 0.51 dextrose saline given intravenously over 30 minutes at $6.0 \mathrm{pm}$ on 25 January and at 8.0 am and $6.0 \mathrm{pm}$ on the next two days, that is, $5.0 \mathrm{~g}$ in total.

The data show that the patient definitely absorbed a great deal of lead, yet he never had any symptoms or signs of poisoning. It was six months from the date of the accident before he returned two consecutive spot urine samples of less than $0.72 \mu \mathrm{mol} / 1$ (150 $\mu \mathrm{g} \mathrm{Pb/l)}$.
The urinary lead levels give a better understanding of the degree of absorption compared with the blood lead or the urinary ALA.

The effect of chelation with intravenous calcium disodium versenate was similar to that seen in tetraethyl lead poisoning.

\section{Comparison with tetraethyl lead poisoning}

There have been many reports in the literature of poisoning by tetraethyl lead, usually in leaded gasoline tank cleaners, and it is possible to compare the clinical effects and biological data of these cases with the present patient. These data are shown in Table 2. Only those series using 24-hour samples are compared.

In the individual exposed to tetramethyl lead, the 24 hours' output of lead in urine was considerably higher than in the cases of tetraethyl lead poisoning. All the patients exposed to tetraethyl lead had symptoms, some of a very severe nature, but no symptoms developed in the individual exposed to tetramethyl lead.

\section{Effects of chelation therapy}

Boyd et al. (1957) used intravenous EDTA on patients with tetraethyl lead poisoning, and Beattie et al. (1972) used D-penicillamine, in a dosage of $900 \mathrm{mg}$ by ingestion on three patients with tetraethyl lead poisoning. The urinary excretion of lead in those cases, compared with the present patient, is shown in Table 3.

The results confirm Boyd's (1957) conclusion that a relatively large excretion of lead occurs in the first few days after treatment, but not as great as that seen in inorganic lead poisoning. Nevertheless, it would appear that treatment with intravenous 
TABLE 2

Comparison of Cases of Tetraethyl Lead Poisoning with Case of Tetramethyl lead Poisoning

\begin{tabular}{|c|c|c|c|c|c|c|c|c|}
\hline \multirow{2}{*}{\multicolumn{2}{|c|}{ Author }} & \multirow{2}{*}{$\begin{array}{l}\text { Toxic } \\
\text { agent }\end{array}$} & \multirow{2}{*}{ Symptoms } & \multirow{2}{*}{ Signs } & \multicolumn{2}{|c|}{ Urinary $\mathrm{Pb} / 24 \mathrm{H}$} & \multicolumn{2}{|c|}{ Blood Pb } \\
\hline & & & & & $\mu \mathrm{mol}$ & $(\mu g)$ & $\mu \mathrm{mol} / \mathrm{l}$ & $(\mu g / 100 g)$ \\
\hline $\begin{array}{l}\text { Boyd, } \\
\text { Walker, and } \\
\text { Henderson } \\
\text { (1957) }\end{array}$ & $\begin{array}{l}1 . \\
2 . \\
3 .\end{array}$ & $\begin{array}{l}\text { TEL } \\
\text { TEL } \\
\text { TEL }\end{array}$ & $\begin{array}{l}\text { Anxiety state } \\
\text { Anxiety state } \\
\text { Anxiety state }\end{array}$ & $\begin{array}{l}\text { Minimal } \\
\text { Weight loss } \\
\text { Pulse depressed } \\
\text { BP, pulse, tempera- } \\
\text { ture all depressed }\end{array}$ & $\begin{array}{l}3 \cdot 32 \\
1 \cdot 30 \\
1.07\end{array}$ & $\begin{array}{l}(688)^{*} \\
(270)^{*} \\
(222)^{*}\end{array}$ & $\begin{array}{l}2 \cdot 46 \\
3 \cdot 04 \\
2 \cdot 70\end{array}$ & $\begin{array}{l}(51) \\
(63) \\
(56)\end{array}$ \\
\hline $\begin{array}{l}\text { Beattie, } \\
\text { Moore, and } \\
\text { Goldberg } \\
(1972)\end{array}$ & 1. & $\begin{array}{l}\text { TEL } \\
\text { TEL } \\
\text { TEL }\end{array}$ & $\begin{array}{l}\text { Restlessness } \\
\text { Insomnia } \\
\text { Agitation } \\
\text { Confusion } \\
\text { Agitation } \\
\text { Disturbing dreams } \\
\text { Acute toxic } \\
\text { delirium }\end{array}$ & $\begin{array}{l}\text { Anxiety tremor } \\
\text { Nil } \\
\text { Nil }\end{array}$ & $\begin{array}{l}3 \cdot 68 \\
2 \cdot 47 \\
3 \cdot 40\end{array}$ & $\begin{array}{l}(762) \\
(512) \\
(705)\end{array}$ & $\begin{array}{r}3 \cdot 86 \\
4 \cdot 44 \\
3 \cdot 19\end{array}$ & $\begin{array}{l}(80) \\
(92) \\
(66)\end{array}$ \\
\hline Gething & 1. & TML & Nil & Nil & $4 \cdot 75$ & $(983)^{* *}$ & 3.91 & (81) \\
\hline
\end{tabular}

* Mean figure for two days

**Mean figure for four days

TABLE 3

EFFECTS OF Chelation

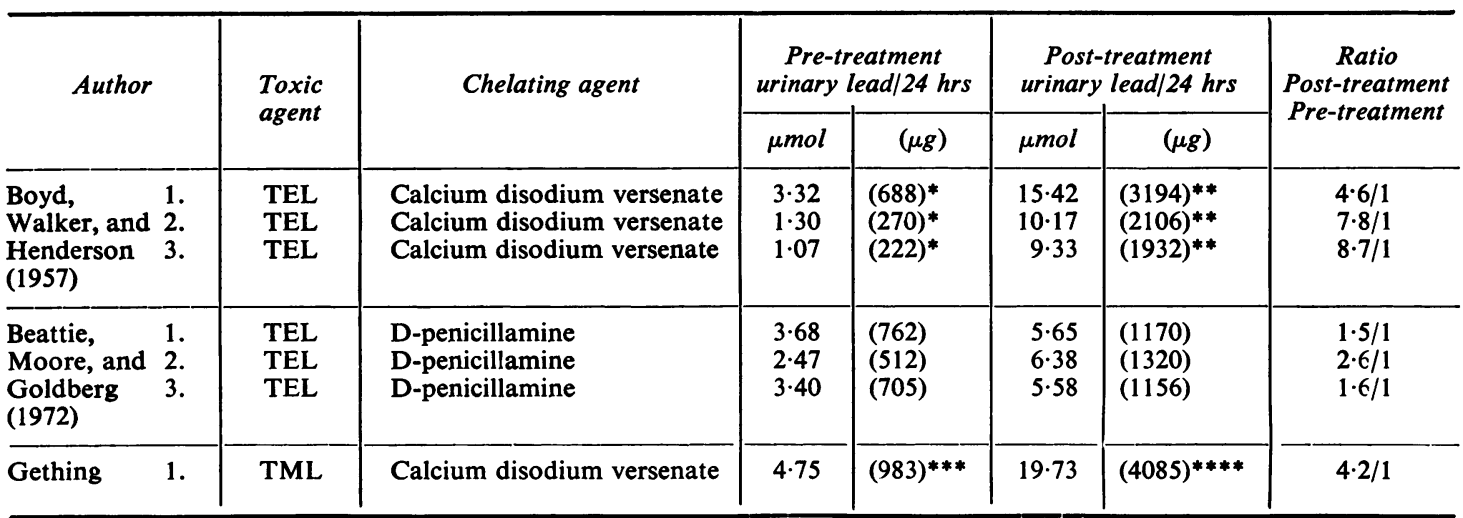

*Mean of two days

**Mean of three days

*** Mean of four days

****Mean of five days

calcium disodium versenate is justified in patients with a high level of absorption of tetramethyl lead.

\section{Discussion}

Animal experiments by Cremer (1959) using tetraethyl lead showed that it was the tri-ethyl radical which was the toxic agent. Springman et al. (1963) have compared the effects of trimethyl lead and triethyl lead by ingestion in rats and concluded that the two substances were similar in toxic response and mortality. They also went on to say that, assuming that the conversion of tetramethyl lead to trimethyl lead is the normal metabolic process, then some factor retards the build-up of an effective concentration of trimethyl lead in the susceptible neurological areas of the organism.

Paradoxically, Davis et al. (1963) showed that tetramethyl lead was considerably more toxic than tetraethyl lead when the dog was used as the experimental animal.

Further work by Cremer and Calloway (1961) 
using rats and rabbits showed a slower rate of conversion of tetramethyl lead to trimethyl lead when given intravenously to rats compared with the conversion of tetraethyl lead to triethyl lead. They also concluded from inhalation studies on rats that tetramethyl lead given by this route had less than one-tenth of the toxicity of tetraethyl lead.

It is not possible to draw firm conclusions from a single case of high tetramethyl lead absorption, but when comparing this case with previously reported cases of poisoning by tetraethyl lead the following observations would seem reasonable:

Blood lead estimations and the urinary excretion of ALA are of little value in determining the severity of absorption of tetramethyl lead.

Similar conclusions have been reached in cases of tetraethyl lead poisoning (Beattie et al., 1972; Gutniak, Koziolowa, and Kowalski, 1964).

The effect of calcium disodium versenate would appear to be similar in both tetraethyl lead poisoning and excessive exposure to tetramethyl lead.

From the evidence of the accident reported in this case and the high levels of lead in urine, there is no doubt that the patient was exposed to and absorbed tetramethyl lead.

The urinary lead levels were higher than in patients with symptoms of tetraethyl lead poisoning, including psychosis and acute toxic delirium.

Yet at no time did the patient show any symptoms, nor did repeated physical examination yield any sign of disease.

It would seem that this one human case confirms results of previous work with animals and indicates that tetramethyl lead is less toxic to humans than tetraethyl lead.

By what margin its toxicity is less it is not possible to say with any accuracy.

\section{References}

Bambach, K. and Burkey, R. E. (1942). Microdetermination of lead by dithizone. Industrial and Engineering Chemistry, 14, 904-907.
Barry, P. S. I. (1957). A recent case of mild tetraethyl lead intoxication. Transactions of the Association of Industrial Medical Officers, 7, 71-73.

Beattie, A. D., Moore, M. R., and Goldberg, A. (1972). Tetraethyl lead poisoning. Lancet, 2, 12-15.

Boyd, P. R., Walker, G., and Henderson, I. N. (1957). The treatment of tetraethyl lead poisoning. Lancet, 1 , 181-185.

Browett, E. V. and Moss, R. (1965). Manual and semiautomatic methods for the determination of the lead content of urine. Analyst, 90, 715-726.

Cassells, D. A. K. and Dodds, E. C. (1946). Tetraethyl lead poisoning. British Medical Journal, 2, 681-685.

Cremer, J. E. (1959). Biochemical studies on the toxicity of tetraethyl lead and other organo-lead compounds. British Journal of Industrial Medicine, 16, 191-199.

- and Callaway, S. (1961). Further studies on the toxicity of some tetra and trialkyl lead compounds. British Journal of Industrial Medicine, 18, 277-282

Davis, J. R. and Andelman, S. L. (1967). Urinary deltaaminolevulinic acid (ALA) levels in lead poisoning. Archives of Environmental Health, 15, 53-59.

Davis, R. K., Horton, A. W., Larson, E. E., and Stemmer, K. L. (1963). Inhalation of tetramethyl lead and tetraethyl lead. Archives of Environmental Health, 6, 473-479.

Gutniak, O., Koziolowa, H., and Kowalski, E. (1964). Free protoporphyrin content of erythrocytes in chronic tetraethyl lead poisoning. Lancet, 2, 11371138.

Kehoe, R. A. (1961). The Harben Lectures, 1960. The metabolism of lead in man in health and disease. Journal of the Royal Institute of Public Health and Hygiene, 24: 81-96, 101-120, 129-143, 177-203.

Springman, F., Bingham, E., and Stemmer, K. L. (1963). The acute effects of lead alkyls. Archives of Environmental Health, 6, 469-472.

Thompson, J. A. (1971). Balance between intake and output of lead in normal individuals. British Journal of Industrial Medicine, 28, 189-194.

Walker, G. and Boyd, P. R. (1952). Tetraethyl lead poisoning. Lancet, 2, 467-469.

Received for publication 21 November 1974

Accepted for publication 12 February 1975 